specific quantity; alkaline reaction; no sugar; no albumen. States that he passes more urine than he should, and is frequently disturbed at night to pass it. Instructed how to collect and measure it, and to bring a sample of the mixed twenty.four hours' urine at the next visit. The patient, however, did not comply with all the conditions necessary for accurate measurement, and it was not till Oct. 21st that I was satisfied that my instructions had been carefully carried out. By that time he had been five weeks under treatment (mineral acids and nux vomica), and had improved to some extent. Analysis of twenty-four hours' urine. -Oct. 21st : Quantity 2300 cc.; sp. gr. 1015 ; reaction alkaline. Phosphoric acid 5.8 grms., or nearly treble what it should be for a man of his weight. Ordered codeia pill, one-third of grain, and a mixture with bromide of potassium and nux vomica.-Nov. 18th: Very much improved; is gaining weight, feels stronger, has nearly lost the pains, discharge of urine still more abundant than it should be. To collect and measure it as before and bring a sample at next visit. To continue mixtures but to discontinue the codeia. - Nov. 25th : Analysis of urine : quantity 2300 ; sp. gr. 1015; reaction alkaline. Phosphoric acid $58 \mathrm{grms}$; 倡ea $33.5 \mathrm{grms}$.

CASE 4. Excessive elimination of phosphoric acid; no polyuria; hypochondriasis; enormous quantities of calcium oxalate in urine -A gentleman's servant, aged twentyseven. First came under observation September 28th, 1880 . $\mathrm{He}$ is a thin spare man, weighing about eight and a half stone ; of sallow, haggard complexion. No history of syphilis ; habits temperate. Complains of aching pains, especially in the loins, shooting down the hips, and occasionally affecting the bladder and testicles. Alleged loss of virile power. Abdominal and thoracic organs apparently healthy. Digestion fair, bowels constipated. Feels very wretched and depressed. Urine passed at the time of visit (11 A.M.) acid; specific gravity 1028, containing eight grms. of phosphoric acid in $1000 \mathrm{cc}$. The secretion of urine, he said, was not excessive; he was rarely troubled during the day, but frequently at night with calls to micturate. (He was requested to collect and measure the urine for a few days, and send a note with regard to the quantity passed in the twenty-four hours; this proved to be just under two pints, or about 1100 cc.) The urine he passed in my presence deposited in a few hours an enormous quantity of oxalate of lime; no sugar; no albumen. Ordered codeia pill, a quarter of a grain, at night, and a mixture of hydrochloric acid in nux vomica and cod-liver oil.-Nov. 18th : Is much better. Less pain in loins. Not so despondent, though still fears he is impotent; confesses, however, to occasional manifestations of "his nature." To discontinue codeia and take phosphorus pills, one-sixtieth of a grain, instead. To collect urine for twenty-four hours and send it for examination.-Dec. 1st : Quantity 1520 cc.; sp. gr. 1022 ; urea 412 grms.; phosphoric acid $5 \cdot 2$ grms. Still under observation.

CASE 5. Polyuria; increased elimination of phosphoric acid, co-existing with a mild form of gly cosuria. - A gentleman aged thirty-seven, who for the last eighteen months has suffered intermittently from a mild form of glycosuria, which did not apparently affect his general health, began in the autumn of the present year (1880) to suffer from constant aching, boring pains in the loins, shooting round the pelvic regions, with occasional cramp-like sensations in the bladder, and a tired, sore feeling in the muscles of the thighs and calves of the legs. He also became dispirited and hypochondriacal ; began to lose weight and flesh. The amount of sugar passed had never been excessive, and had always been controlled by restricted diet. At this time he was certainly not passing more sugar than he had done in the earlier stage of his illness, and it again disappeared when he placed himself on restricted diet for a few days. Still, however, the pains and malaise continued.

On Oct. 12th the urine was collected for twenty-four hours, and subsequently on Oct. 14th and 15th, and Nov. 3rd, 2lst, and 26th. On each occasion the amount of phos phoric acid present was estimated with the following results:

\begin{tabular}{|c|c|c|c|c|c|c|c|}
\hline & Quantity. & & Sp. gr. & Phosphoric aci & & Sugar. & Urea. \\
\hline Oct. 12th & 2020 cc. & . & 1018 & .. $\quad 7 \circ 6$ grms. & .. & & 一 \\
\hline "14th & $2300 \mathrm{cc}$ & .. & 1015 & 6.9 & .. & nil. & - \\
\hline , 15th & $1520 \mathrm{cc}$. & .. & 1020 & $5 \cdot 7$ & . & nil. & — \\
\hline Nop. 3rd & $2500 \mathrm{cc}$. & .. & 1012 & $7 \cdot 5$ & .. & considerable & - \\
\hline , 21st & $2350 \mathrm{cc}$. & .. & 1019 & $8 \cdot 2$ & .. & , & - \\
\hline 26 th & $2300 \mathrm{cc}$. & .. & 1018 & $4 \cdot 6^{*}$, & .. & ," & 9 grms. \\
\hline
\end{tabular}

The patient began taking codeia in half-grain doses at bed-
Oct. 25 th; it was then discontinued, as be was feeling better. On Nov. 3rd the pains, however, returned with considerable severity, and the codeia was resumed, but it was only taken occasionally up to Nov. 20th. Sugar also reappeared in the urine in more considerable amount than had been previously noted and continued till the patient left town. No special reason could be assigned for the reappearance of the sugar, as the diet was in no way different on the days of its reappearance than it had been during the period immediately preceding. That is to say, the diet had been restricted, with the exception of a small quantity of crust of bread taken with each meal. Grain doses of extract of opium were now given at bedtinie till Dec. 4th, when the patient left town for a month's rest. During that time he took no medicine. Most of the holiday was spent at watering-places, where he bathed daily and made use of tepid saline douches; he also took a considerable amount of walking exercise. He returned to town, feeling better in everv respect. He has regained his lost weight, and is now bright, cheerful, and hopeful. The pains in the loins and thighs still, however, trouble him occasionally. The urine (January 15th) on examination gave the following result. Quantity 1900 cc.; sp. gr. 1020 ; urea 66 grms.; phosphoric acid 3.8 grms. ; no sugar.

$$
\text { (To be concluded.) }
$$

\section{THE \\ MECHANICAL TREATMENT OF CROUPOUS MEMBRANE AFTER TRACHEOTOMY.}

BY C. H. GOLDING-BIRD, M.B., F.R.C.S., ASSISTANT SURGEON TO GUY'S HOSPITAL.

IN membranous laryngitis, after tracheotomy has been performed, the case resolves itself, as far as the surgeon is concerned, almost entirely into one of foreign body in the trachea and bronchi, that is if the membrane has already reached so far down; if not, then the dyspncea will be for the time quite relieved by the operation, but in due course the disease having reached the lower parts of the windpipe, symptoms of a foreign body obstructing respiration again appear. The remarks now made and the cases quoted are in illustration of a method of dealing with such a condition as that last named. Usually on the opening of the trachea a suitable silver tube is at once inserted, as much with the idea of stopping blood getting into the trachea as of relieving the dyspnoea. For some time after the child coughs up clots and blood-stained mucus, with perhaps some membrane, while the greatest anxiety is felt lest the tube should become blocked, and very careful cleansing by feathers, \&c., has consequently to be carried out at very frequent intervals; and the patient often does not even then breathe satisfactorily. Such a mode of procedure is mechanically wrong, to say the least of it. Everything save air and a minute amount of mucus in the windpipe is a foreign body; and such are the blood and mucus, as well as the membrane, in every croup case. These can scarcely be expelled vid the glottis, for that is already blocked by membrane, while the chances of their finding their way out through a lateral, rigid, and bent tube, the end of which hangs freely in the trachea, like the stem of a funnel in a wide-mouthed bottle, are very remote. If the tracheotomy tube were of the same calibre as the trachea itself, expectoration would be more easy; but it is not only smaller of necessity, but hangs (or should hang) freely in the lumen of the trachea, and with some degree of mobility. That blood and mucus-let alone the more solid membrane -will be readily forced by natural efforts exactly through the mouth of this tube is unlikely, clinical experience shows; and then these foreign matters collect around or below the tube and are sucked backwards and forwards for long before they hit the right path; while the futile efforts of a piece of membrane to make its exit is announced by a valve-like flapping noise, familiar to all who have had much to do with tracheotomy in croup.

Until therefore the trachea has been cleansed as far as possible from all foreign bodies, the tracheotomy-tube should not be inserted, but other means should be adopted to keep the tracheal wound patent. In eight cases during the last nine months $I$ have acted upon +his rule, employing at first 
the ordinary German nose speculum, as doubuless others have done, instead of a tracheotomy tube, the blades of the instrument being inserted into the tracheal wound, and then screwed open. Although fairly self-retaining, there were many reasons against its being perfect for the purpose, and so the tracheal dilator here figured has been designed. It is inserted, with the blades screwed together, into the trachea, the handle lying against the top of the sternum ; on rapidly turning the screw the blades separate to the required extent, and their shape renders them self-retaining. If desired, tapes can be tied to the blades where they join their bandles, and fastened round the neck, but this is not often requisite. The blades retain their parallelism even when fully open, as they do not work from a hinge, but travel along the double screw. This improvement of the screw over the hinge (which I first employed) was suggested to me by Mr. Lund of Manchester. The same sized dilator does for all cases, whether infants or adults. In any case it may take the place of a tracheotomy tube on an emergency, even when no foreign body has to be extracted. After tracheotomy in every case of membranous laryngitis two distinct mechanical

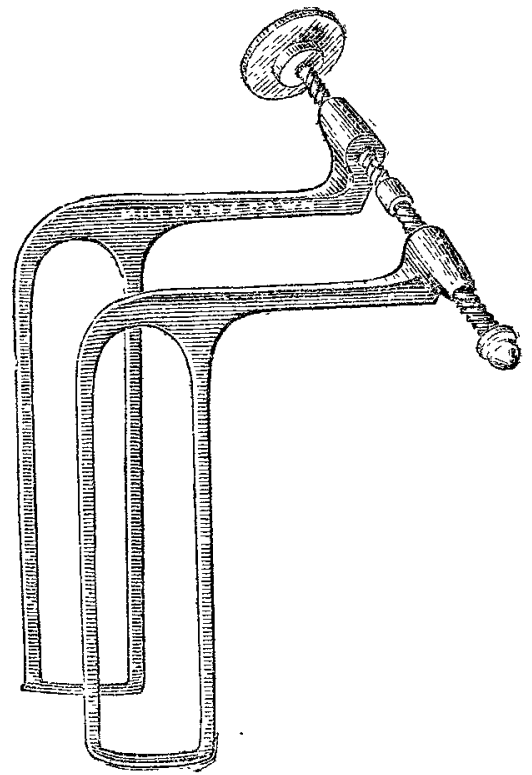

This instrument, as well as the brushes on steel wire, are made by Millikin and Down, St. Thomas's-street, S.E.

problems are presented to the surgeon:-(1) The establishment of a free passage through which membrane, \&c. may be expelled by natural efforts ; or, this failing, (2) its removal by artificial means. In either case, as a preliminary, a sufficiently free opening into the trachea must be madefive-eighths of an inch even in infants, and proportionately longer in older persons. This done, the following steps fulfil as nearly as possible the above requirements :-

(a) At once insert (with the left hand) into the tracheal wound the blades of a pair of dressing forceps, and then open them as widely as possible. Free expectoration of blood, mucus (and perhaps membrane) will follow, and these can be rapidly sponged from the lips of the wound. A clear passage being thus insured, expectoration and coughing are rapidly over and full inspiration restored, while all blood is brought up from the air passages within a few minutes.

(b) To determine the presence of membrane in the trachea (i. e., below the glottis) reflect a strong light into the wound from a mirror on the operator's forehead. If there is no membrane, the posterior wall of the trachea may be seen, pink and moist, and looking very much like the outer wall of the oesophagus. Small pieces of sponge held in dressing forceps can be used to clean it from bubbles of mucus. If healthy it may be taken for granted that there is no membrane below-the formation of membrane proceeding from above downwards. If an inspection be now made in an upward direction through the wound, membrane will perhaps be seen just entering the trachea from the larynx. The operator is at present below the obstruction.

(c) To maintain the tracheal opening patent, a tracheotony tube can be now inserted, until evidence of membrane in the trachea is forthcoming; but supposing this stage now reached, or to have existed at the time of the operation, a tabe is best dispensed with. Instead of dressing forceps or tube, insert the tracheal dilator in to the trachea itself, not only into superficial tissues, and dilate until it holds firmly; the least possible opposition is thus offered to natural expulsive efforts.
An inspection of the trachea will now show either a layer of characteristic membrane or else the mucous surface will have lost its pink colour, be cloudy and white; when this is seen it may be taken as a sure sign of coming membrane. In cases where the membrane has been stripped off and the normal appearance as far as possibie restored, this white cloudiness will be always a sure precursor of a fresh formation.

(d) To remove membrane if seen. If natural efforts have failed the surgeon should (lighted still by the mirror on forehead) remove with forceps (for example, aural polypus forceps) all that can be seen, or that is coughed up to the opening. Membrane may be now searched for below the wound. Minute pieces of sponge held in curved forceps, or feathers, can be passed down ; but I prefer for this purpose a brush, like a rather large pipe cleaner, on strong but flexible steel wire. I at first used Maw's feeding-bottle brushes, but they are very liable to break, and therefore had the stronger ones made. Before use they hould be put into hot water. They may be passed in a child three inches from the wound - that is, well into the first division of the bronchi, and if rotated sharply at the moment of retraction will detach and draw up often large pieces of membrane. When mucus rather than membrane obstructs, feathers and minute sponges are preferable. If the air passages are thus rendered free, the patient can be left again to the nurse with instructions to mop out frequently with small pieces of sponge, held in artery forceps, anything coughed up to the wound; and also, by reflected light, to rick out any visible pieces of membrane. At the same time the usual adjuncts of alkaline and other sprays should be employed. Hot flannels can be placed over the dilator. There is less anxiety to the surgeon now, for there is no tube to get blocked or to be cleaned by the nurse; for the dilator need never be touched even for days, and as the wound granulates it is imbedded and held more and more firmly. It is perfectly comfortable, and seems to give no pain; it causes no irritation, and except in one case, not under my care, where a small abrasion was seen after death of the nucous membrane of the trachea, it has left no mark of its presence. Automatic retractors for the soft parts, during the operation, are recommended by some; but to urge the systematic employment of tracheal dilatation instead of a tracheotomy tube, as long as any foreign body, of whatever kind, has to be got rid of, is the object of this communication.

While the chances of death from suffocation are by this means, I believe, much diminished, the use of the dilator does not seem to influence one way or the other the onset of pneumonia or pleurisy-the usually fatal terminations to croup. Of the eight cases already referred to, four died of pleurisy or pneumonid, two recovered, and two died with suffocative symptoms. Of these, one a girl aged two years and a half, showed on inspection the smaller tubes blocked with membrane, but the trachea and bronchi were quite free, having been cleansed during life and there having been no reformation of the membrane; the other, a boy aged five years, had had the upper air passages cleared of large casts on several occasions, the child each time being completely relieved of all symptoms; at last, however, all efforts to sponge or brush up membrane failed and the child died asphyxiated, the inspection showing a peculiarly adherent membrane in the trachea that required some force to tear off with forceps, while the tubes, both large and small, were lined with membrane of ordinary character and appearance.

The case appended illustrates the points above mentioned. A fatal case is taken that the post-mortem appearances may be noted. The only remarks on cases of recovery would be that the expectoration of membrane gradually gave place to one of muco-pus, and that in its turn to one of simple mucus; between these two last stages the dilator is removed for good.

CASE.-Julia W-, three years and a half old. First seen at $8 \mathrm{~A}$ M. on Dec. $26 \mathrm{th}$, 1880 . Symptoms of dyspnoea for two or three days; now struggling for breath, and semicyanotic. Frothy expectoration. The child's general health, apart from its present attack, not good. Tsacheotomy at once without an anresthetic, and dressing forceps inserted into the wound and opened; blood and numens freely expectorated. Two more rings now cut, and by reflected light a complete cast of the trachea seen, and removed with forceps. A few shreds of membrane were also brought up from below the wound with a feather and brush. Forceps now withdrawn, and tracheal dilator inserted, and the patient returned to her cot breathing comfortably. At 
11 A.M. frothy mucus in the trachea was removed with a feather, and the nurse was provided with artery forceps to hold minute pieces of sponge, or to remove membrane, if any seen. At 6 P.M. the nurse reported membrane brought up on feather; so by reflected light the trachea was again examined, and much membrane removed with a feather and brush; some was coughed into view, and removed with forceps. Child was left breathing comfortably. Ordered carbonate of soda (three grains to one fluid ounce) as spray to trachea twice every hour, or whenever breathing became difficult. At 10 P.M. the child expectorated through the wound much muco-pus. On Dec. 27 th, at 9 A.M., the same report; large tubes seem clear. At 4 P.M. the respiration was very rapid, and symptoms of pueumonia had developed since the morning, and at 7 A.M. on Dec. 28th the child died. Throughout the child had been in a tent, with steam, and had worn the dilator.

Post-mortem examination. - Basic pneumonia; membrane in all the smaller tubes; there was none in the trachea or larger bronchi ; there was no mark to show where the dilator had been worn.

St. Thomas's-street, S.E.

ON THE

\section{ANTIPYRETIC TREATMENT OF TYPHOID FEVER BY MEANS OF SODIUM SALICYLATE.}

BY HENRY TOMKINS, M.D.,

MEDICAL OFFICER TO THE MONSALL FEVER HOSPITAL, MANCHESTER.

THE subject of the treatment of typhoid fever will doubtless by many be considered as one that has been threshed out over and over again without yielding results at all commensurate with the time and labour bestowed upon jt; and perchance there are but few who have not come to the conclusion that whatever be the treatment adopted in this disease, whether most active or most passive, the general results obtained will be of very little practical difference. But whilst we have year by year a death-roll facing us of nearly 10,000 souls of every rank and condition of life, in this country alone, but little apology is needed for again bringing forward any treatment that offers a probable reduction in the above mortality.

At the present time the lines upon which our treatment of typhoid is laid down may be broadly stated äs two-viz., the expectant or non-therapeutic, and the specific or active treatment, this latter having taken the form of a vigorous attack upon the pyrexia of the disease, which is looked upon, and justly so, as one of, if not the most important of all its attendant phenomena. For at the present day no man having any pretension to a rational knowledge of medicine would any more dream of conducting a case of typhoid fever without the constant use of his thermometer, than he would of diagnosing a lung affection without his stethoscope.

It has been truly said that 80 per cent. of all these cases need no medicinal treatment. In a sense this is true; but what about the remaining 20? For the former the "expectant" treatment is sufficient, but when we have to deal with the more severe minority, how helpless do we feel when we see the patient slowly drifting beyond the borderline of safety, the temperature steadily rising and maintaining a degree which, as we know all too well, cannot long be horne by the system without speedily inducing a fatal termination.

If, as is now generally held, all the so-called "zymotics" depend, as we have positive evidence some do, upon the presence within the body of a specific living poison, a true contagium vivum, having properties as distinct and powers of reproduction of its kind as perfect as any genera or species known to botanist or zoologist, then surely it is not an idea so very chimerical that we may have a specific remedy or antidote for each of these living toxic agents ; and although $I$ have no evidence to bring forward that sodium salicylate is a specific remedy, still we know that our most powerful agents for reducing the bady heat are also powerful germicides and preventives of fermentation, quinine standing high on the list, and salicylate of soda still higher, 1 part in 20,600 , if the latter sufficing to perfectly preserve. saccharine liuils from fermentation, anl to arrest the action of myrosin in mustard and other well-known fermentation processes. On this print also may be cited an experiment. made last summer with the shiva if a raid ing. Two others were inoulated from it, the one with soliva pure from the rabid atimal, the other with the same to which 1000th part of salicylate was added. The tormer developed all the symptoms of a severe attack of rajies, and died on the thirteenth day; the other is still alive and well. And could we isolate the typhoid poisem, or cultivate it apart from the body, as with some infective orgauisms, sodium salicylate would possibly prove a certain destroyer of that poison also. Therefore I would suggest only as a possible theory, as we know so little low it acts, that rhe antipyretic powers of this agent may be due to its power as a germicide; the more so as these properties are very much less seen in febrile action due to local inflammations, as pneumonia or pleurisy, than in those where wo have ground for supposing some poisonous principle is circulating in the blood. But putting all theory aside and keeping solely to facts, and using it simply as at remedy for the treatment of a symptom in the typhoid process, the same as we would use styptics for hrmorrhage, alcohol for failing circulation, or sedatives for delirium, we have in it a means, and a most powerful one, of controlling the much-dreaded increased temperature of the body. And here we may briefly consider upon what rational grounds the employment of any antipyretic treatment is $\dot{a}$ priori to be advocated. In typhoid fever we have a disease for which we have no specific remedy that will abort or cut short its career, and all that lies within our power is to treat symptoms as they arise. Amongst its more dangerous manifestations is that of $\approx$ long-sustained high temperature, which not unfrequently becomes the most important factor in our diagnosis, prognosis, and treatment. In the greater number of fatal cases (setting aside those due directly to hæmorrhage and perforation) the patients appear to succumb to the direct effects of the excessive febrile movement; and therefore, if we can with certainty guard against the deleterious influence of this pyrexia, we shall rob the disease of a great part of its terrors. It is undisputed that the rapid degenerative changes found throughout the body, in muscle, glands, and viscera, are due directly to the increased temperature, these changes being found in proportion to the height and duration of the pyrexia; but of even greater importance is the deleterious effect produced upon the heart, and through it upon the circulation and upon the central nervous system. This being so, surely any agent that offers itself as an available weapon with which to combat, if not the specific poison, yet one of its most serious manifestations, is deserving of a fair trial before it is declared to be found wanting.

Does therefore salicylate of soda offer anv, and if so, what, advantages over the means more commonly used to reduce this temperature? Foremost stands at present the cold bath. Many and enthusiastic, especially on the Continent, have been the advocates of this method, but I make bold to say that in the typhoid of this country at least it is not a remedy upon which we can always rely, neither is it always safe; and, chief point of all, it is not capable, and never will be, of daily ordinary application. And as much of the treatment of typhoid is not conducted in hospital, but by the usual medical attendant, it practically is not possible, to say nothing of the prejudice of the patients' friends, to carry out this treatment in the manner that its advocates demand.

Again, even its most ardent supporters, such as Leibermeister of Tübingen, admit that it is not admissible in all cases, as it is apt where there is a bigh degree of cardiac weakness to induce fatal collapse. And the same authority says that, if he were restricteil to the sole use of either the cold bath or quinine, of the two he would prefer the latter. ${ }^{1}$ Quinine without doubt has large powers as an antipyretic, but the doses necessary for the full production of its effects are taken by patients with extreme loathing, and are exceedingly apt to produce nausea, vomiting, and serious disturbance of the stomach, to say nothing of the practical objection to its extensive use from its present high commercial value.

That sodium salicylate is a powerful agent, and one requiring skill and care in its administration, is at once admitted; its physiological effects are powerful and well

\footnotetext{
1 Vide Ziemssen's Encyclopædia, article Typhoid, p. 216.
} 